\title{
Traffic Adaptive MAC Protocols in Wireless Body Area Networks
}

\author{
Farhan Masud, Abdul Hanan Abdullah, Gaddafi Abdul-Salaam, and Fasee Ullah \\ Department of Computer Science, Faculty of Computing, Universiti Teknologi Malaysia (UTM), 81310 Johor, Malaysia \\ Correspondence should be addressed to Farhan Masud; farhan.contact@gmail.com
}

Received 18 July 2016; Accepted 19 October 2016; Published 12 January 2017

Academic Editor: Dario Bruneo

Copyright (C) 2017 Farhan Masud et al. This is an open access article distributed under the Creative Commons Attribution License, which permits unrestricted use, distribution, and reproduction in any medium, provided the original work is properly cited.

\begin{abstract}
In Wireless Body Area Networks (WBANs), every healthcare application that is based on physical sensors is responsible for monitoring the vital signs data of patient. WBANs applications consist of heterogeneous and dynamic traffic loads. Routine patient's observation is described as low-load traffic while an alarming situation that is unpredictable by nature is referred to as high-load traffic. This paper offers a thematic review of traffic adaptive Medium Access Control (MAC) protocols in WBANs. First, we have categorized them based on their goals, methods, and metrics of evaluation. The Zigbee standard IEEE 802.15.4 and the baseline MAC IEEE 802.15.6 are also reviewed in terms of traffic adaptive approaches. Furthermore, a comparative analysis of the protocols is made and their performances are analyzed in terms of delay, packet delivery ratio (PDR), and energy consumption. The literature shows that no review work has been done on traffic adaptive MAC protocols in WBANs. This review work, therefore, could add enhancement to traffic adaptive MAC protocols and will stimulate a better way of solving the traffic adaptivity problem.
\end{abstract}

\section{Introduction}

In recent years, the advancement of Microelectromechanical Systems (MEMS) and sensing technologies has led to the emergence of WBANs, which are now used in advancing human health. WBAN is a wireless technology in which sensors and actuators can be connected in the body, on the body, and off the body, based on radio frequency to monitor the surrounding environment and functions of the body [1]. The sensor nodes are small and lightweight and consume low power. The network of these small, intelligent devices allows users and medical staff to continuously monitor the health of patients and obtain real-time feedback.

The applications of WBAN include vital signs data observation of patient in the hospital, continuous and long life health monitoring, and monitoring of humans working in life-critical areas like war-fields, deep-sea, space, etc. [2]. It is observed that applications of WBAN have both low-rate and high-rate traffic. Therefore, communication protocols in WBAN should have adjustment capabilities to accommodate variations in the dynamic traffic. Moreover, energy preservation should be considered in case of low-load traffic, and a balance is required between packet delivery ratio and energy in the case of high-load traffic [3].
A large number of energy-efficient MAC protocols for WBANs have been proposed. These include [4-19]. Also, there have been some prior works that proposed traffic adaptive MAC protocols for WBANs. These include [3, 2024]. In addition, some traffic adaptive MAC protocols are also proposed for IEEE 802.15 .6 such as $[25,26]$. In this article, we summarize these works and analyze the current research trends that focused on traffic adaptivity issues in WBAN MAC layer. We describe traffic adaptive MAC protocols in WBANs. Then we analyze the MAC superframe structure of IEEE standards based on traffic adaptive approach. The challenges, classification, and comparative analysis of traffic adaptive MAC protocols are also presented.

From the study, we note that traffic adaptive MAC protocols can be classified into three types: traffic load estimation (TLE) based MAC protocols, adaptive wake-up interval (AWI) based MAC protocols, and adaptive time slot allocation (ATSA) based MAC protocols. Moreover, the heterogeneous and dynamic traffic load directly affects performance of communications in terms of delay, PDR, and energy consumption. Therefore, we analyze the protocols in terms of these metrics.

The rest of the paper is organized as follows. Section 2 covers the related work. Section 3 discusses traffic adaptive 
MAC protocols in WBANs. Then, in Section 4, a comparative analysis of traffic adaptive MAC protocols is presented. Finally, in Section 5, the conclusion and future directions are highlighted.

\section{Related Works}

There are many survey works in WBANs. For instance, the paper [27] focuses on the applications, technologies, standards, and design issues of WBANs. The paper describes the issues that affect the performance of WBAN network and provides useful insight for WBAN designers. The paper [28] focuses on WBAN applications and provides a taxonomy to create a clear understanding of WBAN terminology. Also, the paper [29] discusses patient healthcare applications, WBANs communication architecture, and the positioning of WBANs among other wireless networks. It overviews the existing research on the physical layer, MAC protocols, routing protocols, cross layer, and Quality of Service (QoS). It also discusses the existing WBAN projects and points out current challenges and open research issues. Furthermore, the paper [30] discusses the latest standards of WBAN and current research in WBANs in terms of PHY layer, routing, MAC layer, channel modeling, security, address allocation, and applications. The paper [31] discusses communication standards of WBANs, energy, QoS, physical layer, MAC layer, routing layer, and application layer requirements by focussing on the existing research work and technologies.

In [32], Khan et al. provide techniques for healthcare applications and the analysis to design energy-efficient MAC protocols. The authors conclude that a MAC protocol plays a critical role in finding the overall energy efficiency, network throughput, and transmission reliability. Moreover, energy efficiency has been addressed in conventional wireless sensor networks such as in [33]. In [1], Cao et al. discuss sensor devices, radio systems, applications scenarios, and WBANs interconnection in which they present the trade-offs between data rate, network coverage, and power consumption. The article provides a comprehensive review of pioneer research projects and enabling technologies for WBANs. In [34], the authors discuss ambient assisted living (AAL) technologies, tools, and techniques on the basis of ambient intelligence paradigm for people of older age. They provide future challenges in sensor technology, assistive robotics technology, security and privacy, human factors, and algorithms. The paper [35] focuses on energy efficiency, transmission reliability, delay, data rates, and security in WBANs. The authors compare different reliable and energyefficient wireless communications protocols. The paper considers the requirements of healthcare systems with emphasis on effective communication in the home infrastructure. It also discusses the weakness of different WBAN systems in the home infrastructure and proposes a more appropriate system for residential healthcare. Further, it provides a way for healthcare professionals to continuously monitor elderly people and patients in their homes for early detection of abnormal conditions to improve the quality of living. Finally, the paper concludes with a review of existing works in the area of healthcare systems.

Likewise, many studies have generally covered the MAC protocols in WBANs. For example, in [36], Rahim et al. discuss WBAN design requirements in terms of energy dissipation and the existing MAC protocols in the light of their strengths and weaknesses. In [37], Bradai et al. discuss the existing MAC protocols with a focus on the design requirements of WBAN. The authors provide the performance analysis of existing IEEE standards for WBAN MAC and TMAC protocols in various conditions and conclude that end-to-end delay is the worst case for these protocols. Some other studies focus on energy-efficient MAC protocols in WBANs. Among them there is [38] that evaluates energyefficient MAC protocols in terms of wake-up radio of inbody biomedical sensor nodes (BMSNs). The paper [39] also discusses main energy exhausting attacks in MAC protocols and presents energy exhaustion in various MAC protocols due to these attacks. The paper gives directions to researchers for future research in energy-efficient MAC protocols. In addition, some researchers dwell on QoS in MAC protocols. This category includes the paper [40]. It provides analysis of QoS requirements for WBANs, highlights the prerequisites for QoS-aware system, and discusses the current issues of QoS at MAC layer. The paper compares and analyzes the existing QoS-aware MAC protocols in terms of design requirements of QoS in WBANs.

From the above highlighted literature, it can be noted that most of the existing survey works focus on the general applications, technologies, and challenges of WBANs. Clearly, there is no survey work that focuses on the specific protocols such as traffic adaptive MAC protocols in WBANs, and this paper focuses on filling this gap.

\section{Traffic Adaptive MAC Protocols in WBANs}

In WBAN, the human body is observed by heterogeneous sensor nodes; therefore, the applications consist of heterogeneous traffic loads. Moreover, WBAN applications are comprised of variable traffic loads due to emergency traffic. Hence, traffic load estimation is necessary to create a balance between energy and throughput [3]. Either the network model of WBAN follows the star topology, where all BMSNs are attached to a single coordinator [20], or it may also be a tree or a mesh topology, where the BMSNs are attached with cluster heads which are further attached to the coordinator [41]. The MAC is the most appropriate layer to deal with packet delivery ratio and energy efficiency [37, 38, 40, 42-48]. Furthermore, MAC plays a key role in improving the overall performance of the network [49].

The BMSNs operation at MAC layer in the aforementioned WBAN topologies is a challenging job due to many reasons. Firstly, the BMSNs face the problem of data handling due to limited energy and processing power because data rate is variable by nature [3]. For example, the BMSNs that are used to observe heartbeat, body temperature, and blood pressure usually have low-rate traffic. But sometimes traffic load increases due to emergency situations. Moreover, 


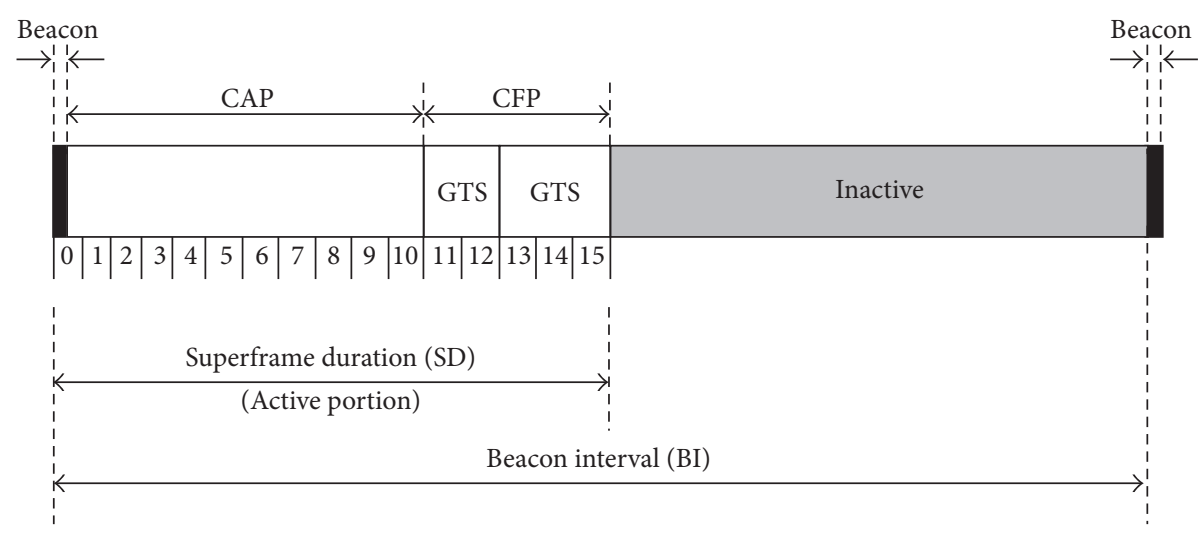

FIGURE 1: General overview of MAC superframe structure of IEEE 802.15.4 beacon-enabled mode [50].

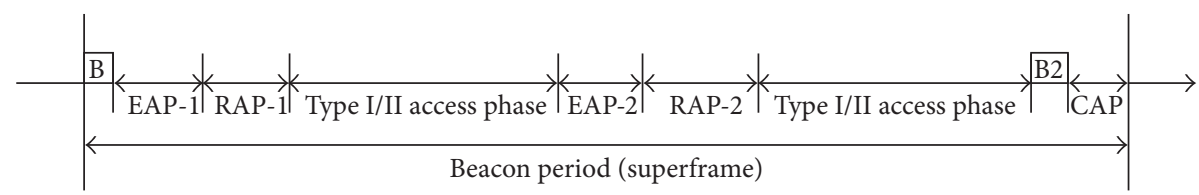

FIGURE 2: IEEE 802.15.6 superframe structure [78].

the BMSNs for real-time ECG signal observation always have high-rate traffic. Secondly, the applications with lowload traffic usually demand energy preservation with the lowest delay and the applications with high-load traffic usually demand high packet delivery ratio with the least possible delay [3]. Therefore, energy preservation should be considered primarily in case of low traffic load, whereas a balance should be required between energy and packet delivery ratio in case of high traffic load. Thirdly, the internal and external interferences and limited channel bandwidth inflict unpredictable and immoderate load on the execution of MAC operations. Hence, a dynamic and scalable MAC protocol for WBANs is required to achieve high energy efficiency and packet delivery ratio with the least possible delay [3].

\subsection{Analysis of MAC Superframe Structure of IEEE Standards Based on Traffic Adaptive Approach}

3.1.1. IEEE 802.15.4. A general overview of MAC superframe structure of IEEE 802.15.4 beacon-enabled mode is given in Figure 1. It consists of active and inactive parts. The active part is further subdivided into equal aNumSuperframeSlots slots. The aNumSuperframeSlots slots are further grouped into a beacon, Contention-Free Period (CFP) and Contention Access Period (CAP). The CFP uses a Time Division Multiple Access (TDMA) approach and CAP uses a slotted Carrier Sense Multiple Access (CSMA) approach.

However, IEEE 802.15.4 has its inherent drawbacks that allow only up to seven Guaranteed Time Slots (GTSs) [50], not enough for WBAN applications [20, 21, 24, 51, 52]. The superframe cannot be dynamically adjusted due to the fixed length of active and inactive periods. In particular, the superframe structure of IEEE 802.15.4 is not traffic load adaptive [20].

3.1.2. IEEE 802.15.6. The superframe structure of IEEE 802.15.6 beacon-enabled mode is given in Figure 2. It consists of Exclusive Access Phase (i.e., EAP-I/II), Random Access Phase (i.e., RAP-I/II), Type I/II phase, and Contention Access Period (CAP) followed by optional beacon (B2) frame. Each phase has dynamic length and can be removed by assigning zero length. EAP-I and EAP-II are used for high priority traffic while, RAP-I, RAP-II, and CAP are used for other types of traffic. Furthermore, Type I/II phases are provided for scheduled uplink, downlink, and bilink allocations.

However, IEEE 802.15.6 has the capability to dynamically adjust EAP-I, EAP-II, RAP-I, and RAP-II based on the heterogeneous and dynamic traffic loads. In particular, the superframe structure of IEEE 802.15.6 is traffic load adaptive.

3.2. Challenges of Traffic Adaptive MAC Protocols in WBANs. The major goal of traffic adaptive MAC protocols is a dynamic adjustment of the superframe for variable and heterogeneous traffic loads based on traffic load estimation. Moreover, traffic must be classified and prioritized on the basis of their QoS requirements. Hence, the following properties are generally required in designing traffic adaptive MAC protocols.

3.2.1. Traffic Classification. The traffic classification is required for traffic adaptive MAC protocols based on delay and packet delivery ratio. The MAC protocols for WBANs usually classify the traffic into Critical Traffic (CT), Reliability Traffic (RT), Delay Traffic (DT), and Normal Traffic (NT) 


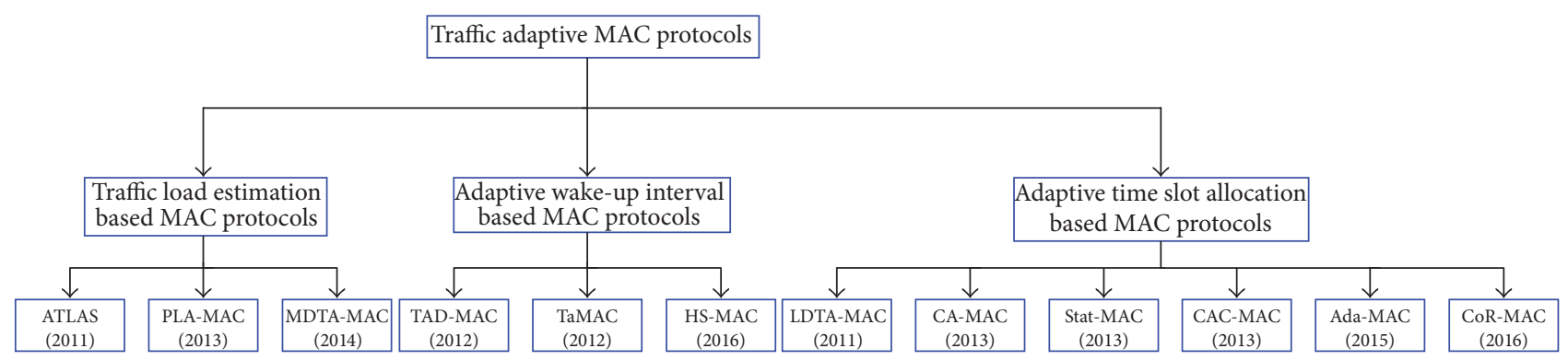

FIgUre 3: Classification of traffic adaptive MAC protocols in WBANs.

[21, 26, 51, 53]. Besides, some MAC protocols address another special class of traffic referred to as emergency traffic [54-63]. But, practically, classification of traffic is context-dependent [53].

3.2.2. Traffic Prioritization. Traffic prioritization in WBAN is usually practiced in two ways. One way is that the highest priority is assigned to emergency traffic, second highest priority is assigned to Critical Traffic, third highest priority is assigned to reliability-constrained traffic, fourth highest priority is assigned to delay-constrained traffic, and the lowest priority is assigned to Normal Traffic [53]. The other way is that traffic prioritization is calculated through the traffic class value and the data generation rate of the particular BMSN [21]. Many MAC protocols perform traffic prioritization [6473].

3.2.3. Traffic Load Estimation (TLE). Traffic load estimation in WBAN is done through different ways. The first way is that the radio capacity usage of the nodes is checked at the particular time interval and is communicated to the Body Coordinator (BC) periodically. And the second way is that the traffic load estimation is based on data generation rate of BMSNs. The dynamic adjustment of variable and heterogeneous traffic loads is done on the basis of TLE.

3.3. Classification of Traffic Adaptive MAC Protocols in WBANS. In WBANs, the sensor nodes are heterogeneous by nature and are used to monitor vital signs data. This inherent feature of WBANs sensor nodes results in different traffic loads (e.g., traffic load is low in case of periodic observation and high in case of sporadic burst). Hence, in designing MAC protocols for WBANs, dynamic adjustment of traffic based on different traffic loads should be considered. The traffic adaptive MAC protocols in WBANs that consider dynamic adjustment of traffic by various traffic loads can be classified into three types: traffic load estimation based MAC protocols, adaptive wake-up interval based MAC protocols, and adaptive time slot allocation based MAC protocols. In the subsequent sections, we explain each of them in detail. Likewise, the different existing approaches that use them are summarized and reviewed in detail. Figure 3 shows the existing state-of-the-art approaches in the classification tree.
3.3.1. Traffic Load Estimation (TLE) Based MAC Protocols. The paper [3] proposes A Traffic Load Aware Sensor (ATLAS) MAC design to improve energy efficiency, PDR, and packet delivery delay. The authors propose four modes of the superframe on the basis of traffic load by using traffic load estimation as presented in Figure 4. Moreover, traffic load is classified into four classes consisting of low load, moderate load, high load, and overload. The traffic load estimation is done at every cluster head by its radio capacity usage measurement in a particular time interval as presented in

$$
L_{i}=\frac{T_{c} \times\left(\mathrm{ar}_{i}^{s}+\mathrm{fr}_{i}^{s}+\mathrm{cr}_{i}\right)}{c \times \eta \times T_{c}}=\frac{\left(\mathrm{ar}_{i}^{s}+\mathrm{fr}_{i}^{s}+\mathrm{cr}_{i}\right)}{c \times \eta} \text {, }
$$

where $L_{i}$ is the load index at the particular cluster head, $T_{c}$ represents the superframe duration, $c$ is the radio capacity, and $\eta$ shows the maximum usage of radio capacity. Also, $\operatorname{ar}_{i}^{s}$ represents the successful packet arrival rate, $\mathrm{fr}_{i}^{s}$ shows the successful packet forwarding rate, and $\mathrm{cr}_{i}$ represents the packet collision rate at particular cluster head.

This traffic load estimate is transmitted with data and beacon packet by each cluster head to the gateway node. The gateway node adjusts superframe's mode for communication based on received traffic load estimations. The gateway advertises Ack beacon in the beginning of every beacon interval to announce the superframe operation mode based on traffic load estimation. ATLAS improves energy efficiency in case of low traffic load and creates a balance between energy consumption and PDR with low delay in case of high traffic load. However, ATLAS ignores traffic prioritization [26].

The paper [21] introduces a traffic Priority and Load Adaptive MAC (PLA-MAC) protocol to reduce energy consumption with traffic load estimation based traffic prioritization. The authors propose a traffic load aware MAC protocol for WBANs. In PLA-MAC, the traffic is differentiated into four classes on the basis of data type and data rate of the sensor nodes. The prioritization among the sensor nodes is done through prioritized random back-off. The length of inactive period is adjusted dynamically based on the network traffic load. The superframe structure of PLA-MAC 

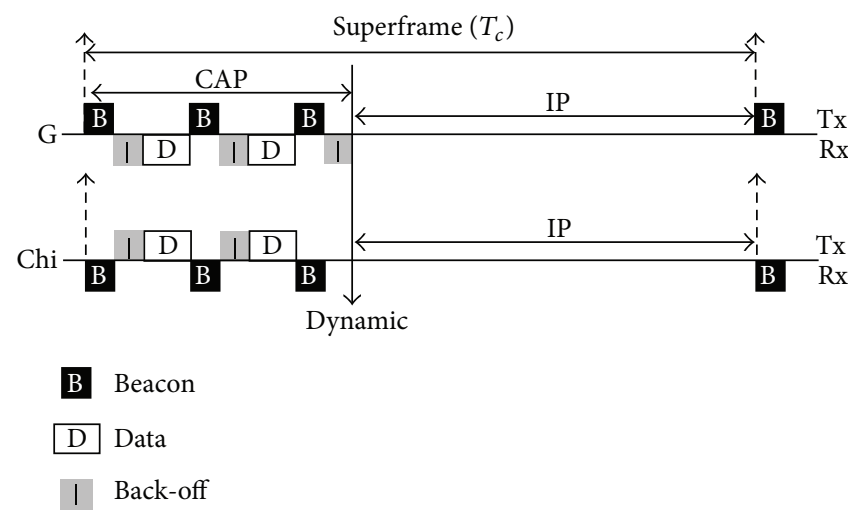

Back-off

(a)

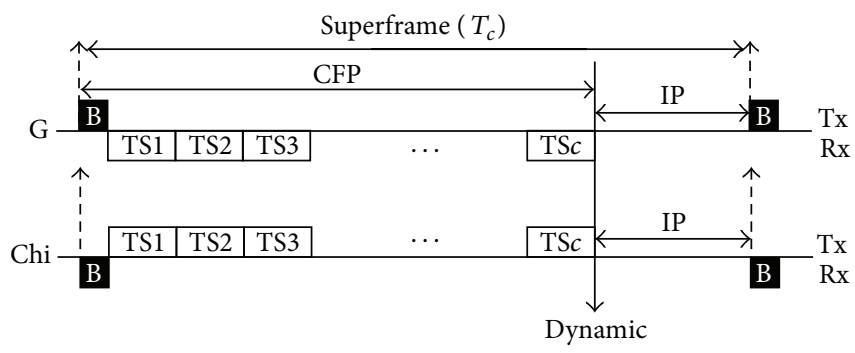

B Beacon

TS Time slot

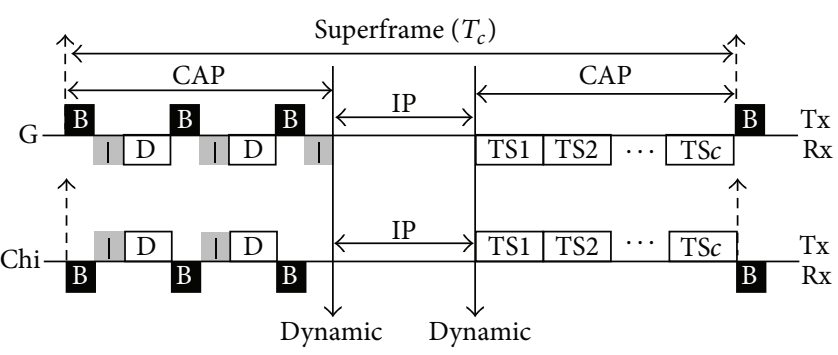

B Beacon

D Data

I Back-off

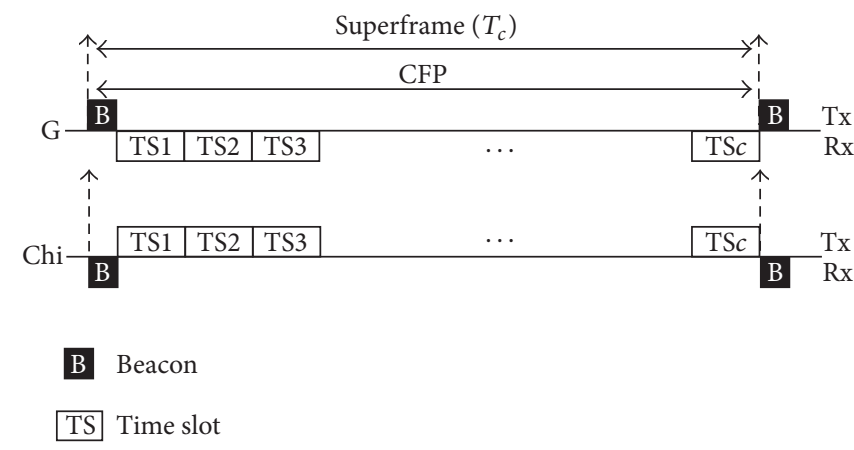

(d)

Figure 4: Communication from cluster head to gateway (Chi-to-G): (a) low load, (b) moderate load, (c) high load, and (d) overload [3].

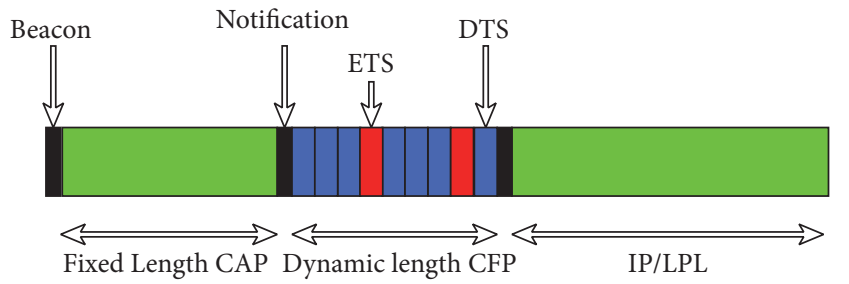

ETS: emergency data transfer slot

DTS: data transfer slot

LPL: low power listening

IP: inactive period

FIGURE 5: Superframe structure of PLA-MAC [21].

is presented in Figure 5 and the equation to calculate the priority is presented in

$$
P_{i}=\frac{T_{i}}{G_{i} \times S_{i}},
$$

where $P_{i}$ represents the priority, $T_{i}$ represents the traffic class value, $G_{i}$ represents the data generation rate, and $S_{i}$ represents size in bytes of the particular packet. The PLA-MAC improves the delay and PDR. However, PLA-MAC does not consider diverse traffic loads [26].
The paper [26] presents a Multidimensional Traffic Adaptive MAC (MDTA-MAC) protocol to achieve energy efficiency with low delay using traffic load estimation. The proposed protocol performs traffic classification and prioritization. Also, traffic is classified into four classes. In MDTA-MAC, traffic load is categorized as low load, moderate load, high load, and overload. Additionally, traffic load is calculated (by using (3)) at each sensor node and sporadically transmitted to the gateway. Hence, the gateway announces the next operational mode of the superframe. Two operational modes are considered in MDTA-MAC: one is considered for low-load traffic and the other one is considered for other types of traffic loads. Figure 6 presents the operational modes of the superframe in the case of different traffic loads.

$$
L_{i}=\frac{\mathrm{TAD}_{p}}{Q_{c}},
$$

where $L_{i}$ represents the load index, $\mathrm{TAD}_{p}$ represents the total amount of data packets, and $Q_{c}$ represents the queue capacity at a particular MAC cycle $i$. The MDTA-MAC performs well in energy efficiency and PDR. However, in MDTAMAC, when traffic load increased, it also increases the packet delivery delay.

3.3.2. Adaptive Wake-Up Interval (AWI) Based MAC Protocols. The paper [25] proposes a Traffic-Aware Dynamic 


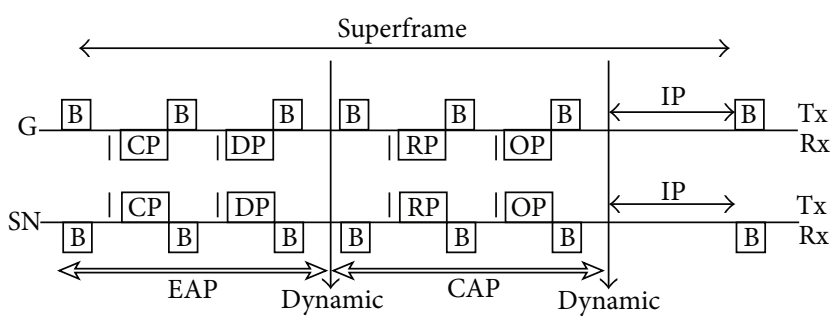

B Beacon

$\mathrm{CP}$ Critical data packets

DP Delay-driven data packets

\begin{abstract}
| Back-off and contention window
RP Reliability-driven data packets

$\mathrm{OP}$ Ordinary data packets
\end{abstract}

(a)

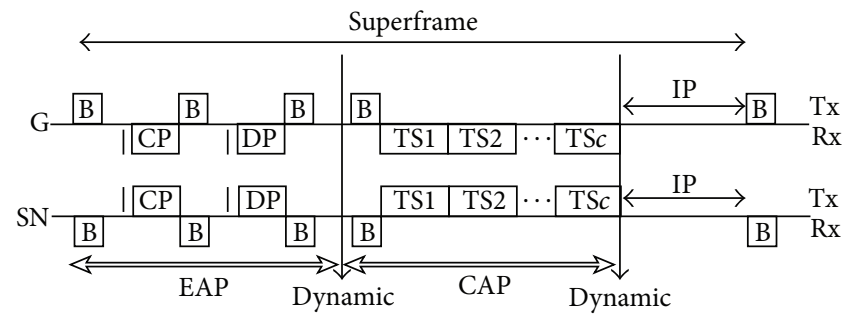

B Beacon
CP Critical data packets
| Back-off and contention window

(b)

FIGURE 6: Superframe structure for (a) low load and (b) moderate load, high load, and overload [26].

MAC (TAD-MAC) protocol to reduce energy consumption using adaptive wake-up interval approach. In TAD-MAC, the authors present an adaptive algorithm using CSMA/CA approach. According to this algorithm, every sensor node has its own Traffic Status Register (TSR). The coordinator determines the accurate wake-up interval for each sensor node through the bank of TSR on the basis of traffic load. TAD-MAC manages overhearing, idle listening, packet collision ratio, and packet overheads very well to reduce energy consumption. However, TAD-MAC is inappropriate for WBANs due to its preamble-based approach because biomedical sensor nodes routinely transmit the sensory information outside the human body and it increases the preamble cost of energy constrained biomedical sensor nodes [74].

The paper [60] introduces a traffic adaptive MAC (TaMAC) protocol to improve energy efficiency. The authors consider diverse traffic types of WBAN applications to improve energy efficiency. In TaMAC, the traffic is classified into normal, emergency, and on-demand traffic. The emergency traffic is considered as unpredictable traffic. A trafficbased wake-up mechanism is used for Normal Traffic while a wake-up radio mechanism is used for on-demand and emergency traffic. This protocol analyzes the data delivery delay and energy efficiency of the system. In performance evaluation, IEEE 802.15.4 MAC, WiseMAC, and SMAC protocols are considered for comparison. The results reveal that TaMAC performs better in energy conservation and delay. However, the wake-up response signal and beacon sending time result in high delay during the transmission of emergency data. Furthermore, TaMAC considers only periodic traffic and does not consider traffic load burst on multiple sensor nodes simultaneously due to emergency traffic [62].

A Heuristic Self-Adaptive MAC (HS-MAC) protocol is proposed in [75] to improve energy efficiency and decrease packet delivery delay. The authors propose a traffic estimation technique with convergence patterns of sensor nodes at the coordinator. They provide a heuristic representation for the previously proposed traffic adaptive algorithm TAD-MAC
[25] as a nonlinear control system to study the convergence behavior of algorithmic parameters. The authors design and evaluate open-loop and closed-loop forms for this purpose. Furthermore, they explain the convergence patterns in detail. They have also designed a state machine for MAC protocol and use WSNet network simulator for performance analysis. The following performance metrics are used: delay, PDR, energy consumption, and convergence time. The authors use a star topology for WBAN network to check the values of the aforementioned performance metrics for diverse traffic rates. In addition, they have evaluated the energy consumption for both transmitter and receiver sensor nodes based on diverse characteristics of the traffic. They further evaluated the different convergence times that are best, average, and worst. This protocol performs well regarding delay and energy efficiency. However, the packet loss ratio is increased from $0 \%$ to $30 \%$ in the worst convergence time. Hence, the packet delivery ratio is reduced.

3.3.3. Adaptive Time Slot Allocation (ATSA) Based MAC Protocols. The paper [20] proposes Low Delay and Traffic Adaptive MAC (LDTA-MAC) protocol to reduce power consumption and packet delivery delay with the management of diverse traffic loads. It provides dynamic adjustment of traffic on the basis of traffic load and intends to reduce packet delivery delay as well as improve packet throughput. Figure 7 presents the superframe structure of LDTA-MAC, which has extended CFP with a dynamic boundary towards an inactive period. The paper uses notification period before extended CFP to announce slot allocation schedule in extended CFP by the coordinator for the sensor nodes, which sends the request during CAP period. Also, the extended CFP could be extended up to the end of the beacon interval based on traffic load. The LDTA-MAC performs well regarding delay, throughput, and energy conservation. However, the limited and fixed CAP results in low throughput during high-load traffic times and high energy consumption during low-load traffic times [3].

A hybrid Context-Aware and traffic adaptive MAC (CA$\mathrm{MAC}$ ) protocol is proposed in [22] to improve energy 


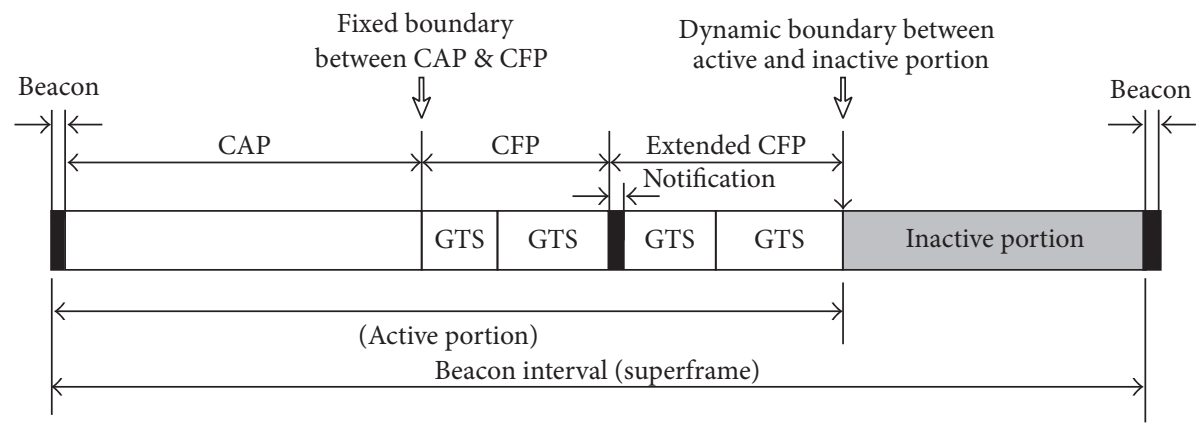

FIgURE 7: The superframe structure of LDTA-MAC [20].

efficiency and to reduce delay with real-time diverse traffic management. It is a traffic adaptive and context-aware MAC protocol. The authors dynamically adjust the duty cycle of each sensor node for all kinds of traffic to reduce the packet delivery delay. In addition, they also dynamically adjust the data rate of every sensor node to make the proposed protocol traffic adaptive. The proposed superframe dynamically adjusts contention access and contention-free periods based on traffic load but it has fixed length duration as presented in Figure 8. The first beacon is fired by the coordinator to synchronize biomedical sensor nodes and to create the communication links. If the channel conditions are changed, then the next beacon is fired by the coordinator to announce an updated structure of superframe on the basis of current traffic load status. The context analysis is done by the coordinator which removes a lot of computation burden from the sensor nodes. There are two subparts of TDMA based CFP: scheduling based and polling based slots. The scheduled based slots are allocated by the coordinator on the basis of the request of sensor nodes during CAP. In the other case, the polling based slots are allocated by the coordinator in case of emergency data occurrence through poll messages; otherwise these slots remain inactive. The CA-MAC is better in delay, PDR, and energy. However, in CA-MAC, the dynamic traffic adjustment does not depend upon traffic load estimation.

A Statistical MAC (Stat-MAC) protocol in WBANs for diverse traffic is proposed in [76] to improve energy efficiency with low delay by providing a scheme for the retransmission of lost messages during inactive period. Here, TDMA is used with periodic synchronization. The authors perform an adaptive time slot allocation to manage heterogeneous traffic. They use a request frame to manage the information about sensor nodes request. The overall scheduling information is broadcasted by statistical frame. They also have used the statistical frame to increase sleep time of the sensor nodes and to generate low duty cycles in each beacon period. The adaptive time slot allocation increases the energy efficiency of Stat-MAC protocol. Furthermore, the authors have analyzed data delivery delay for real-time applications. Stat-MAC performs well in terms of energy efficiency. However, the test-bed is based on only two sensor nodes which is not the practical approach for WBANs. Moreover, the data delivery delay is increased with the increasing timeline(s).

The Context-Aware and Channel-Based MAC (CAC-MAC) protocol is presented in [23] to achieve energy efficiency with traffic prioritization and traffic load based resource allocation. The authors propose traffic prioritization and dynamic superframe adjustment on the basis of channel conditions. The Emergency TDMA (ETDMA) is proposed to transmit emergency data packets, Medical CAP (MCAP) is proposed to transmit emergency alarm, Normal TDMA (NTDMA) is proposed to transmit medical period data, and emergency slot (ES) is used for emergency detection and for context-aware slot allocation, as presented in Figure 9. All the subperiods of the proposed superframe structure have dynamic length except emergency slot. Moreover, the coordinator dynamically adjusts the superframe subperiods based upon the traffic load to reduce the packet loss ratio. It performs well in terms of energy efficiency. However, it does not allocate resources for diverse traffic loads based on traffic load estimation.

An Adaptive MAC (Ada-MAC) protocol for real-time and reliable communications is proposed in [24] to reduce packet loss ratio and packet collision ratio with the adjustment of dynamic traffic loads. The authors propose the MAC protocol for WBANs with the aim of achieving reliability. The CSMA/CA mechanism is used during CAP period and they suggested the dynamic boundary for CFP period extendable to the end of the beacon interval based upon the traffic load. They further subdivide each GTS of CFP period into minislots and assign a whole GTS to the sensor node. Moreover, every sensor node switches off its radio just after the completion of its data transmission during CFP to reduce the energy cost. They use the slotted CSMA/CA approach for routine traffic during CAP period but, in the case of emergency traffic, they use a prioritized back-off for collision avoidance. They use a prioritized queue mechanism for diverse traffic allocation. The Ada-MAC shows good performance regarding delay and packet loss ratio. However, Ada-MAC uses multiple queues for diverse traffic prioritization like IEEE 802.11e standard which is not a practical approach for WBANs [53].

The contention-over-reservation MAC (CoR-MAC) protocol is proposed in [77] to reduce the transmission delay of emergency data. The authors propose a priority-based hybrid MAC protocol for WBANs based on contention over reservation mechanism, as presented in Figure 10. In CoR-MAC, every time slot is dedicated to a particular sensor node that may require sending emergency data. If the dedicated time slots are underutilized and other sensor 


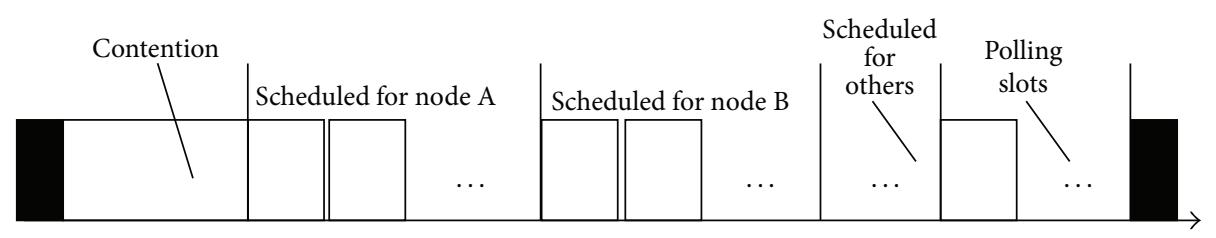

Downlink beacon

Uplink

(a)
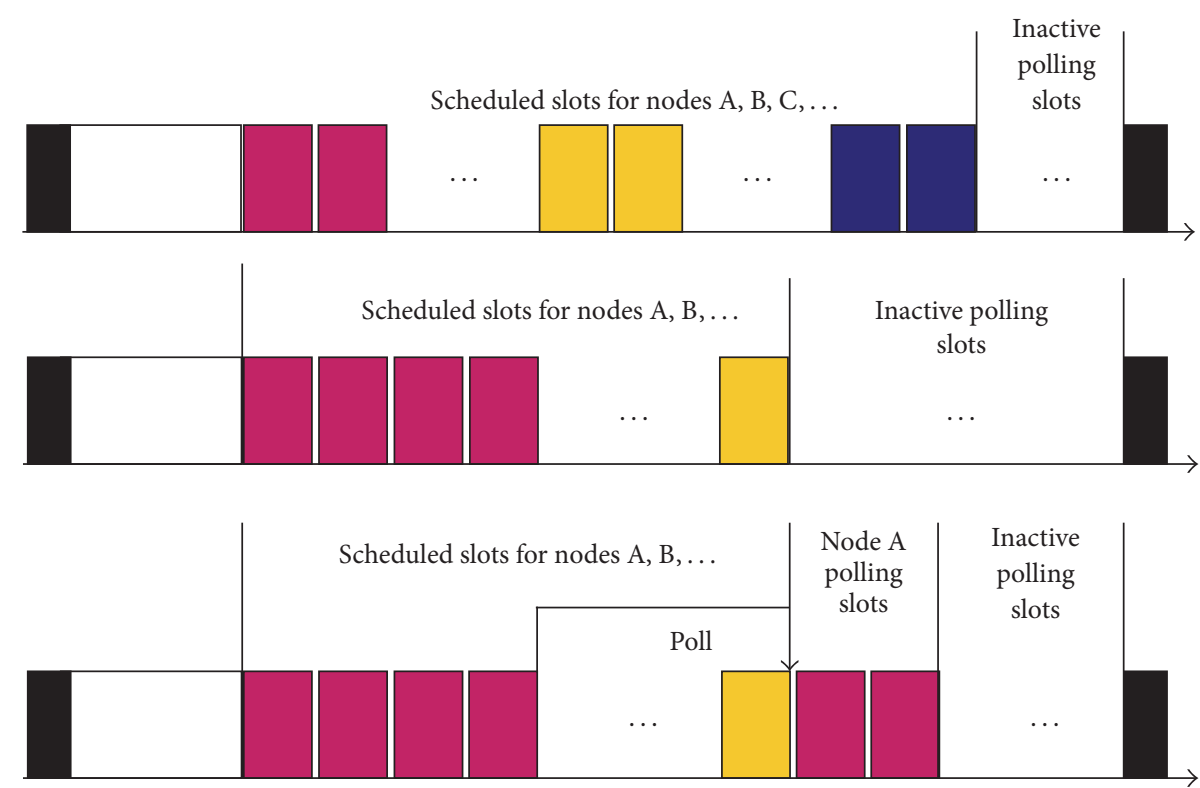

Beacon

Node B

Contention

Node C

Node A

(b)

Figure 8: (a) Superframe structure of CA-MAC. (b) Dynamic traffic adjustment of contention-free slots in the superframe [22].

nodes cannot use those free time slots, then a problem arises which wastes the wireless resources due to dedicated time slots. This problem is solved by CoR-MAC through traffic adaptive approach by transmitting the data over time slots that are dedicated to other sensor nodes which do not use them. This method shows improvement performance in data delivery delay of up to $50 \%-85 \%$. However, in the case of nontime-critical data, the average delay is increased by increasing the number of sensor nodes.

\section{Comparative Analysis of Traffic Adaptive MAC Protocols}

WBANs face the problem of heterogeneous and variable traffic loads and various researchers have proposed different solutions. In Table 1, we compare the already discussed traffic adaptive MAC protocols in WBANs on the basis of the discussed metrics.

ATLAS [3] minimizes the energy consumption and delay while increasing the PDR. However, ATLAS ignores traffic prioritization [26]. PLA-MAC [21] intends to achieve energy efficiency with prioritization based traffic load awareness and shows high performance regarding delay and PDR. However, it does not follow diverse traffic loads [26]. MDTA-MAC [26] intends to improve energy with the low Delay Traffic load management. It performs well in terms of energy and packet delivery ratio but the delay rises due to increasing traffic load.

TAD-MAC [25] aims to improve energy efficiency with traffic adaptive approach. However, it becomes inappropriate for WBANs due to its preamble-based approach because biomedical sensor nodes routinely transmit the sensory information outside the human body. This increases the preamble cost of biomedical limited energy sensor nodes 


\begin{tabular}{|l|l|l|l|l|l|}
\hline Beacon & ETDMA & MCAP & NTDMA & CAP & ES \\
\hline
\end{tabular}

(a)

\begin{tabular}{|l|l|l|l|l|l|}
\hline Beacon & ETDMA & MCAP & CAP & ES & NTDMA \\
\hline
\end{tabular}

(b)

Figure 9: Superframe of CAC-MAC [23].

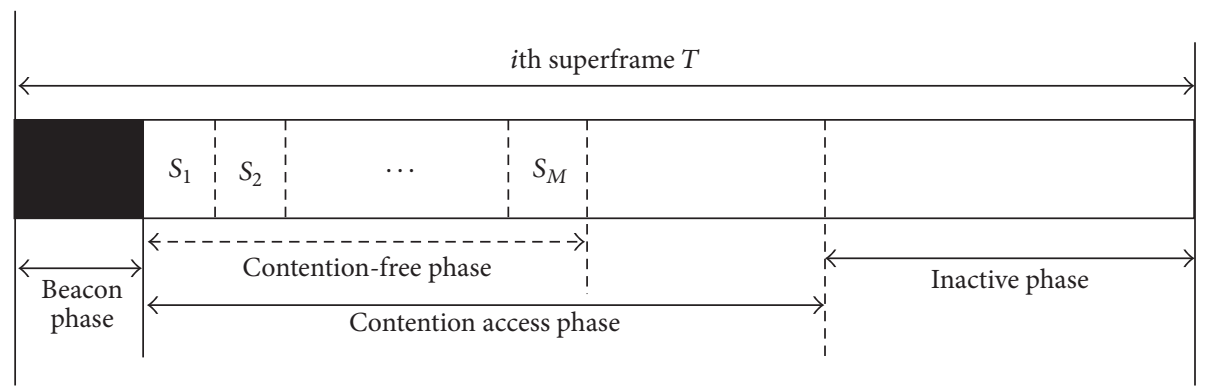

FIGURE 10: Contention over reservation based superframe structure of CoR-MAC [77].

[74]. TaMAC [60] aims to provide a data transfer model for emergency traffic with energy efficiency. Meanwhile, the wake-up response signal and beacon sending time result in high delay during the transmission of emergency data. Furthermore, TaMAC considers only periodic traffic and does not look at multiple sensor nodes with simultaneous emergency traffic [62]. A Heuristic Self-Adaptive MAC [75] protocol aims to reduce delay and increase energy efficiency. The protocol performs well regarding delay and energy. But the packet loss ratio is increased from $0 \%$ to $30 \%$ in the worst convergence time that directly reduces the packet delivery ratio.

LDTA-MAC [20] which aims to reduce delay and power consumption with the management of diverse traffic loads performs well in terms of delay, throughput, and energy consumption. However, the limited and fixed CAP results in wastage of energy during low traffic load and reduces throughput during high traffic load [3]. CA-MAC [22] which aims to improve energy efficiency and reduce delay with realtime diverse traffic management gives good improvement in delay, PDR, and energy. However, it does not estimate traffic load for dynamic traffic adjustment. Stat-MAC [76] which aims to improve energy efficiency with low delay by providing a scheme for the retransmission of lost messages during inactive period performs well in terms of energy efficiency but the test-bed is based on only two sensor nodes. This is not the practical approach for WBANs. Moreover, the data delivery delay increases with increasing timeline(s).

CAC-MAC [23] intends to achieve energy efficiency with traffic prioritization and traffic load based resource allocation. But it does not perform resource allocation for diverse traffic loads based on traffic load estimation. AdaMAC [24] sets its goal to reduce packet loss ratio and packet collision ratio with the adjustment of dynamic traffic loads. Indeed, it scores well in delay and packet loss ratio. However, it uses multiple queues for diverse traffic prioritization like
IEEE 802.11e standard, which is not a practical approach for WBANs [53]. CoR-MAC [77] aims to reduce the transmission delay of emergency data and performs well in terms of data delivery delay. However, the average delay is increased in case of non-time-critical data with the increasing number of sensor nodes.

From the comparison of the traffic adaptive MAC protocols in Table 1, we derive the following conclusions: LDTAMAC [20], ATLAS [3], PLA-MAC [21], CA-MAC [22], and CoR-MAC [77] perform well in reducing delay and increasing packet delivery ratio. HS-MAC [75] shows low packet delivery ratio during the worst convergence time. CAC-MAC [23] shows low energy consumption while PLAMAC [21] shows high energy consumption. Finally, StatMAC [76] and TaMAC [60] do not consider packet delivery ratio and Ada-MAC [24] does not consider energy.

\section{Conclusions and Future Directions}

WBAN applications consist of heterogeneous and dynamic traffic loads. Routine patient's observation is considered as low-load traffic while in alarming situation traffic is considered as high-load traffic. In general, the paper discusses the traffic adaptive MAC protocols in WBANs. The existing IEEE standards for WBANs are discussed in the light of traffic adaptive approach. Furthermore, the challenges of traffic adaptive MAC protocols in WBANs are explained. Moreover, it provides a classification of the existing traffic adaptive approaches. Also, a comparative analysis of the traffic adaptive MAC protocols is presented and their strengths and weaknesses are highlighted. Finally, the performance of these traffic adaptive MAC protocols in WBANs is discussed in terms of delay, packet delivery ratio, and energy consumption.

The future traffic adaptive MAC protocols for WBANs need to perform dynamic time slot allocation based on 
TABLE 1: Comparative analysis of traffic adaptive MAC protocols.

\begin{tabular}{|c|c|c|c|c|c|c|c|c|c|}
\hline \multirow{2}{*}{ Categorization } & \multirow{2}{*}{ Protocol } & \multicolumn{8}{|c|}{ Characteristics } \\
\hline & & Goal & DAT & TLC & Delay & PDR & $\begin{array}{l}\text { Energy } \\
\text { Cons. }\end{array}$ & Strength & Weakness \\
\hline \multirow{3}{*}{ TLE based } & $\begin{array}{l}\text { ATLAS } \\
(2011)\end{array}$ & $\begin{array}{l}\text { To reduce energy } \\
\text { consumption and delay, } \\
\text { increase packet delivery } \\
\text { ratio }\end{array}$ & Yes & Yes & Low & High & Low & $\begin{array}{l}\text { Improve } \\
\text { energy } \\
\text { efficiency and } \\
\text { throughput }\end{array}$ & $\begin{array}{l}\text { Traffic } \\
\text { prioritization is } \\
\text { ignored }\end{array}$ \\
\hline & $\begin{array}{l}\text { PLA-MAC } \\
(2013)\end{array}$ & $\begin{array}{l}\text { To achieve energy } \\
\text { efficiency with } \\
\text { prioritization based } \\
\text { traffic load awareness }\end{array}$ & Yes & Yes & Low & High & High & $\begin{array}{l}\text { Reduce delay } \\
\text { and increase } \\
\text { PDR }\end{array}$ & $\begin{array}{l}\text { Ignore diverse } \\
\text { traffic loads }\end{array}$ \\
\hline & $\begin{array}{l}\text { MDTA- } \\
\text { MAC } \\
(2014)\end{array}$ & $\begin{array}{l}\text { To improve energy with } \\
\text { low delay with traffic } \\
\text { load management }\end{array}$ & Yes & Yes & High & Medium & Low & $\begin{array}{l}\text { Improve } \\
\text { energy } \\
\text { efficiency and } \\
\text { PDR }\end{array}$ & $\begin{array}{l}\text { Delay increases } \\
\text { due to increase in } \\
\text { traffic load }\end{array}$ \\
\hline \multirow{3}{*}{ AWI based } & $\begin{array}{l}\text { TAD-MAC } \\
\quad(2012)\end{array}$ & $\begin{array}{l}\text { To improve energy } \\
\text { efficiency with traffic } \\
\text { adaptive approach }\end{array}$ & Yes & No & NC & NC & Low & $\begin{array}{l}\text { Improve } \\
\text { energy } \\
\text { efficiency }\end{array}$ & $\begin{array}{l}\text { Inappropriate for } \\
\text { WBANs due to its } \\
\text { preamble-based } \\
\text { approach }\end{array}$ \\
\hline & $\begin{array}{l}\text { TaMAC } \\
(2012)\end{array}$ & $\begin{array}{l}\text { To improve energy } \\
\text { efficiency and QoS for } \\
\text { diverse traffic with low } \\
\text { delay }\end{array}$ & Yes & No & High & NC & Medium & $\begin{array}{l}\text { Improve } \\
\text { energy } \\
\text { efficiency }\end{array}$ & $\begin{array}{l}\text { Time-critical } \\
\text { traffic is delayed } \\
\text { by the wake-up } \\
\text { response signal } \\
\text { and beacon } \\
\text { sending time }\end{array}$ \\
\hline & $\begin{array}{l}\text { HS-MAC } \\
(2016)\end{array}$ & $\begin{array}{l}\text { To improve energy } \\
\text { efficiency by using } \\
\text { traffic-based adaptive } \\
\text { wake-up Interval }\end{array}$ & Yes & No & Low & Low & Medium & $\begin{array}{l}\text { Improve } \\
\text { energy } \\
\text { efficiency with } \\
\text { low delay }\end{array}$ & $\begin{array}{l}\text { Packet loss ratio } \\
\text { is increased in the } \\
\text { worst case }\end{array}$ \\
\hline \multirow{5}{*}{ ATSA based } & $\begin{array}{l}\text { LDTA- } \\
\text { MAC } \\
(2011)\end{array}$ & $\begin{array}{l}\text { To reduce delay and } \\
\text { power consumption } \\
\text { with the management of } \\
\text { diverse traffic loads }\end{array}$ & Yes & No & Low & High & Low & $\begin{array}{l}\text { Adaptive slot } \\
\text { allocation } \\
\text { based on traffic } \\
\text { load }\end{array}$ & $\begin{array}{l}\text { Fixed CAP } \\
\text { reduces energy } \\
\text { efficiency during } \\
\text { low load and } \\
\text { throughput } \\
\text { during high load }\end{array}$ \\
\hline & $\begin{array}{l}\text { CA-MAC } \\
(2013)\end{array}$ & $\begin{array}{l}\text { To improve energy } \\
\text { efficiency and to reduce } \\
\text { delay with real-time } \\
\text { diverse traffic } \\
\text { management }\end{array}$ & Yes & No & Low & High & Medium & $\begin{array}{l}\text { Reduce delay } \\
\text { and improve } \\
\text { PDR }\end{array}$ & $\begin{array}{l}\text { No traffic load } \\
\text { estimation }\end{array}$ \\
\hline & $\begin{array}{l}\text { Stat-MAC } \\
(2013)\end{array}$ & $\begin{array}{l}\text { To improve energy } \\
\text { efficiency with low delay } \\
\text { by providing a scheme } \\
\text { for the retransmission of } \\
\text { lost messages during } \\
\text { inactive period }\end{array}$ & Yes & No & Medium & NC & Low & $\begin{array}{l}\text { Improve } \\
\text { energy } \\
\text { efficiency }\end{array}$ & $\begin{array}{l}\text { Experiment based } \\
\text { on two sensor } \\
\text { nodes and delay } \\
\text { increases by the } \\
\text { increment in } \\
\text { timeline(s) }\end{array}$ \\
\hline & $\begin{array}{c}\text { CAC-MAC } \\
(2013)\end{array}$ & $\begin{array}{l}\text { To achieve energy } \\
\text { efficiency with } \\
\text { prioritization traffic load } \\
\text { based resource } \\
\text { allocation }\end{array}$ & Yes & No & Medium & Medium & Low & $\begin{array}{l}\text { Improve } \\
\text { energy } \\
\text { efficiency }\end{array}$ & $\begin{array}{l}\text { No traffic load } \\
\text { estimation }\end{array}$ \\
\hline & $\begin{array}{l}\text { Ada-MAC } \\
(2015)\end{array}$ & $\begin{array}{l}\text { To reduce packet loss } \\
\text { ratio and packet } \\
\text { collision ratio with the } \\
\text { adjustment of dynamic } \\
\text { traffic loads }\end{array}$ & Yes & No & Medium & Medium & NC & $\begin{array}{l}\text { Reduce delay } \\
\text { and improve } \\
\text { PDR }\end{array}$ & $\begin{array}{l}\text { Multiple queues } \\
\text { for diverse traffic } \\
\text { prioritization is } \\
\text { not a practical } \\
\text { approach for } \\
\text { WBANs }\end{array}$ \\
\hline
\end{tabular}


TABLE 1: Continued.

\begin{tabular}{|c|c|c|c|c|c|c|c|c|c|}
\hline \multirow{2}{*}{ Categorization } & \multirow{2}{*}{ Protocol } & \multicolumn{8}{|c|}{ Characteristics } \\
\hline & & Goal & DAT & TLC & Delay & PDR & $\begin{array}{c}\text { Energy } \\
\text { Cons. }\end{array}$ & Strength & Weakness \\
\hline & $\begin{array}{c}\text { CoR-MAC } \\
(2016)\end{array}$ & $\begin{array}{l}\text { To reduce the } \\
\text { transmission delay of } \\
\text { emergency data }\end{array}$ & Yes & No & Low & High & Low & $\begin{array}{l}\text { Reduce data } \\
\text { delivery delay } \\
\text { and shows } \\
\text { better delay } \\
\text { performance } \\
\text { that is } \\
\text { improved from } \\
50 \%-85 \%\end{array}$ & $\begin{array}{l}\text { The average delay } \\
\text { of } \\
\text { non-time-critical } \\
\text { data increases by } \\
\text { the increasing } \\
\text { number of nodes }\end{array}$ \\
\hline
\end{tabular}

DAT = dynamic adjustment of traffic, TLC $=$ Traffic Load Calculation, PDR = packet delivery ratio, and NC = Not Considered.

estimated network traffic. They need to provide mechanisms to conserve energy during low traffic loads. Moreover, they should also create a balance between high packet delivery ratio and energy consumption with the least possible delay during high traffic loads. All these represent open challenges for future work.

\section{Competing Interests}

The authors declare that there is no conflict of interests regarding the publication of this paper.

\section{References}

[1] H. Cao, V. Leung, C. Chow, and H. Chan, "Enabling technologies for wireless body area networks: a survey and outlook," IEEE Communications Magazine, vol. 47, no. 12, pp. 84-93, 2009.

[2] M. A. Hanson, H. C. Powell Jr., A. T. Barth et al., "Body area sensor networks: challenges and opportunities," Computer, vol. 42, no. 1, pp. 58-65, 2009.

[3] M. O. Rahman, C. S. Hong, S. Lee, and Y.-C. Bang, "ATLAS: a traffic load aware sensor MAC design for collaborative body area sensor networks," Sensors, vol. 11, no. 12, pp. 11560-11580, 2011.

[4] S. J. Marinković, E. M. Popovici, C. Spagnol, S. Faul, and W. P. Marnane, "Energy-efficient low duty cycle MAC protocol for wireless body area networks," IEEE Transactions on Information Technology in Biomedicine, vol. 13, no. 6, pp. 915-925, 2009.

[5] H. Li and J. Tan, "Heartbeat-driven medium-access control for body sensor networks," IEEE Transactions on Information Technology in Biomedicine, vol. 14, no. 1, pp. 44-51, 2010.

[6] S. Rezvani and S. A. Ghorashi, "A Novel WBAN MAC protocol with improved energy consumption and data rate," KSII Transactions on Internet and Information Systems, vol. 6, no. 9, pp. 2302-2322, 2012.

[7] B. Manzoor, N. Javaid, A. Bibi, Z. A. Khan, and M. Tahir, "Noise filtering, channel modeling and energy utilization in wireless body area networks," in Proceedings of the IEEE 14th International Conference on High Performance Computing and Communications \& the IEEE 9th International Conference on Embedded Software and Systems (HPCC-ICESS '12), pp. 17541761, IEEE, Liverpool, UK, June 2012.

[8] A. Rahim, N. Javaid, M. Aslam, U. Qasim, and Z. A. Khan, "Adaptive-reliable medium access control protocol for wireless body area networks," in Proceedings of the 9th Annual IEEE
Communications Society Conference on Sensor, Mesh and Ad Hoc Communications and Networks (SECON '12), pp. 56-58, IEEE, Seoul, Republic of Korea, June 2012.

[9] X. Cai, J. Yuan, X. Yuan et al., "Energy-efficient relay MAC with dynamic power control in wireless body area networks," KSII Transactions on Internet and Information Systems, vol. 7, no. 7, pp. 1547-1568, 2013.

[10] J. S. Choi and J. G. Kim, "An energy efficient MAC protocol for WBAN through flexible frame structure," Information, vol. 17, no. 2, pp. 2333-2343, 2014.

[11] M. Maman, D. Miras, and L. Ouvry, "Implementation of a self-organizing, adaptive, flexible and ultra low-power MAC protocol for wireless Body Area Networks," in Proceedings of the IEEE 24th Annual International Symposium on Personal, Indoor, and Mobile Radio Communications (PIMRC '13), pp. 1737-1742, IEEE, London, UK, September 2013.

[12] I. Kirbas, A. Karahan, A. Sevin, and C. Bayilmis, "isMAC: an adaptive and energy-efficient MAC protocol based on multichannel communication for wireless body area networks," KSII Transactions on Internet and Information Systems, vol. 7, no. 8, pp. 1805-1824, 2013.

[13] N. Javaid, A. Ahmad, A. Rahim, Z. A. Khan, M. Ishfaq, and U. Qasim, "Adaptive medium access control protocol for wireless body area networks," International Journal of Distributed Sensor Networks, vol. 2014, Article ID 254397, 10 pages, 2014.

[14] X. Cai, J. Li, J. Yuan, W. Zhu, and Q. Wu, "Energy-aware adaptive topology adjustment in wireless body area networks," Telecommunication Systems, vol. 58, no. 2, pp. 139-152, 2015.

[15] A. Ahmad, N. Javaid, Z. A. Khan, M. Imran, and M. Alnuem, "IA-MAC: improved Adaptive Medium Access Control protocol for Wireless Body Area Networks," in Proceedings of the 14th International Symposium on Communications and Information Technologies (ISCIT '14), pp. 156-160, IEEE, Incheon, Republic of Korea, September 2014.

[16] R. Venkateswari, S. S. Rani, and S. K. A. Meeravali, "A robust MAC protocol for wireless body sensor network," Journal of Scientific \& Industrial Research, vol. 74, no. 6, pp. 334-337, 2015.

[17] V. Esteves, A. Antonopoulos, E. Kartsakli, M. Puig-Vidal, P. Miribel-Català, and C. Verikoukis, "Cooperative energy harvesting-adaptive MAC protocol for WBANs," Sensors, vol. 15, no. 6, pp. 12635-12650, 2015.

[18] R. H. Kim and J. G. Kim, "Delay reduced MAC protocol for bio signal monitoring in the WBSN environment," Advanced Science and Technology Letters, vol. 94, pp. 42-46, 2015. 
[19] M. Shu, D. Yuan, C. Zhang, Y. Wang, and C. Chen, "A MAC protocol for medical monitoring applications of wireless body area networks," Sensors, vol. 15, no. 6, pp. 12906-12931, 2015.

[20] C. Li, B. Hao, K. Zhang, Y. Liu, and J. Li, "A novel medium access control protocol with low delay and traffic adaptivity for wireless body area networks," Journal of Medical Systems, vol. 35 , no. 5, pp. 1265-1275, 2011.

[21] I. Anjum, N. Alam, M. A. Razzaque, M. Mehedi Hassan, and A. Alamri, "Traffic priority and load adaptive MAC protocol for QoS provisioning in body sensor networks," International Journal of Distributed Sensor Networks, vol. 9, no. 3, Article ID 205192, pp. 1-9, 2013.

[22] B. Liu, Z. Yan, and C. W. Chen, "MAC protocol in wireless body area networks for E-health: challenges and a contextaware design," IEEE Wireless Communications, vol. 20, no. 4, pp. 64-72, 2013.

[23] S. Rezvani and S. A. Ghorashi, "Context aware and channelbased resource allocation for wireless body area networks," IET Wireless Sensor Systems, vol. 3, no. 10, pp. 16-25, 2013.

[24] F. Xia, L. Wang, D. Zhang, D. He, and X. Kong, "An adaptive MAC protocol for real-time and reliable communications in medical cyber-physical systems," Telecommunication Systems, vol. 58, no. 2, pp. 125-138, 2015.

[25] M. M. Alam, O. Berder, D. Menard, and O. Sentieys, “TADMAC: traffic-aware dynamic MAC protocol for wireless body area sensor networks," IEEE Journal on Emerging and Selected Topics in Circuits and Systems, vol. 2, no. 1, pp. 109-119, 2012.

[26] M. U. Hossain, Dilruba, M. Kalyan, M. R. Rana, and M. O. Rahman, "Multi-dimensional traffic adaptive energy-efficient MAC protocol for wireless body area networks," in Proceedings of the 9th International Forum on Strategic Technology (IFOST '14), pp. 161-165, IEEE, Chittagong, Bangladesh, October 2014.

[27] R. Cavallari, F. Martelli, R. Rosini, C. Buratti, and R. Verdone, "A survey on wireless body area networks: technologies and design challenges," IEEE Communications Surveys and Tutorials, vol. 16, no. 3, pp. 1635-1657, 2014.

[28] A. F. Jaimes and F. R. Desousa, "A taxonomy for learning, teaching, and assessing wireless body area networks," in Proceedings of the IEEE Latin American Symposium on Circuits \& Systems (LASCAS '16), Florianópolis, Brazil, 2016.

[29] B. Latré, B. Braem, I. Moerman, C. Blondia, and P. Demeester, "A survey on wireless body area networks," Wireless Networks, vol. 17, no. 1, pp. 1-18, 2011.

[30] S. Movassaghi, M. Abolhasan, J. Lipman, D. Smith, and A. Jamalipour, "Wireless body area networks: a survey," IEEE Communications Surveys and Tutorials, vol. 16, no. 3, pp. 16581686, 2014.

[31] V. Ayatollahitafti, M. A. Ngadi, and J. B. M. Sharif, "Requirements and challenges in body sensor networks: a survey," Journal of Theoretical and Applied Information Technology, vol. 72, no. 2, pp. 227-238, 2015.

[32] J. Y. Khan, M. R. Yuce, G. Bulger, and B. Harding, "Wireless body area network (wban) design techniques and performance evaluation," Journal of Medical Systems, vol. 36, no. 3, pp. 14411457, 2012.

[33] M. H. Anisi, G. Abdul-Salaam, and A. H. Abdullah, "A survey of wireless sensor network approaches and their energy consumption for monitoring farm fields in precision agriculture," Precision Agriculture, vol. 16, no. 2, pp. 216-238, 2015.

[34] P. Rashidi and A. Mihailidis, "A survey on ambient-assisted living tools for older adults," IEEE Journal of Biomedical and Health Informatics, vol. 17, no. 3, pp. 579-590, 2013.
[35] M. Ghamari, B. Janko, R. S. Sherratt, W. Harwin, R. Piechockic, and C. Soltanpur, "A survey on wireless body area networks for ehealthcare systems in residential environments," Sensors, vol. 16, no. 6, pp. 831-864, 2016.

[36] A. Rahim, N. Javaid, M. Aslam, Z. Rahman, U. Qasim, and Z. A. Khan, "A comprehensive survey of mac protocols for wireless body area networks," in Proceedings of the 7th International Conference on Broadband, Wireless Computing, Communication and Applications (BWCCA '12), pp. 434-439, IEEE, Victoria, Canada, November 2012.

[37] N. Bradai, L. C. Fourati, and L. Kamoun, "Investigation and performance analysis of MAC protocols for WBAN networks," Journal of Network and Computer Applications, vol. 46, pp. 362373, 2014.

[38] V. R. K. Ramachandran, B. J. Van Der Zwaag, N. Meratnia, and P. J. M. Havinga, "Evaluation of MAC protocols with wake-up radio for implantable body sensor networks," in Proceedings of the International Conference on Selected Topics in Mobile and Wireless Networking (MoWNet '14), pp. 173-180, Rome, Italy, September 2014.

[39] M. Jo, L. Han, N. D. Tan, and H. P. In, "A survey: energy exhausting attacks in MAC protocols in WBANs," Telecommunication Systems, vol. 58, no. 2, pp. 153-164, 2015.

[40] A. Thapa and S. Shin, "QoS provisioning in wireless body area networks," KSII Transactions on Internet and Information Systems, vol. 6, no. 5, pp. 1267-1285, 2012.

[41] M. Chen, S. Gonzalez, A. Vasilakos, H. Cao, and V. C. M. Leung, "Body area networks: a survey," Mobile Networks and Applications, vol. 16, no. 2, pp. 171-193, 2011.

[42] M. J. Miller and N. H. Vaidya, "A MAC protocol to reduce sensor network energy consumption using a wakeup radio," IEEE Transactions on Mobile Computing, vol. 4, no. 3, pp. 228242, 2005.

[43] T. Chiras, M. Paterakis, and P. Koutsakis, "Improved medium access control for wireless sensor networks-a study on the SMAC protocol," in Proceedings of the 14th IEEE Workshop on Local and Metropolitan Area Networks (LANMAN '05), Crete, Greece, September 2005.

[44] A. Barroso, U. Roedig, and C. Sreenan, " $\mu$-MAC: an energyefficient medium access control for wireless sensor networks," in Proceedings of the 2nd European Workshop onWireless Sensor Networks (EWSN '05), pp. 70-80, IEEE, Istanbul, Turkey, February 2005.

[45] T. Zheng, S. Radhakrishnan, and V. Sarangan, "PMAC: an adaptive energy-efficient MAC protocol for wireless sensor networks," in Proceedings of the 19th IEEE International Parallel and Distributed Processing Symposium (IPDPS '05), Denver, Colo, USA, 2005.

[46] G. F. G. Fang and E. Dutkiewicz, "BodyMAC: energy efficient TDMA-based MAC protocol for wireless body area networks," in Proceedings of the 9th International Symposium on Communications and Information Technology (ISCIT '09), pp. 1455-1459, IEEE, Incheon, South Korea, September 2009.

[47] S. Ullah and C. Li, "Energy-efficient MAC protocols for WBANs: opportunities and challenges," Telecommunication Systems, vol. 58, no. 2, pp. 109-110, 2015.

[48] Z. A. Khan, M. B. Rasheed, N. Javaid, and B. Robertson, "Effect of packet inter-arrival time on the energy consumption of beacon enabled MAC protocol for body area networks," Procedia Computer Science, vol. 32, pp. 579-586, 2014.

[49] S. A. Gopalan and J.-T. Park, "Energy-efficient MAC protocols for wireless body area networks: survey," in Proceedings of the 
International Congress on Ultra Modern Telecommunications and Control Systems and Workshops (ICUMT '10), pp. 739-744, IEEE, Moscow, Russia, October 2010.

[50] Society, I.C. IEEE Standard for Local and metropolitan area networks-Part 15. 4: Low-Rate Wireless Personal Area Networks (LR-WPANs), 2011, IEEE Standard Association, https://standards.ieee.org/findstds/standard/802.15.4-2011.html.

[51] J. S. Yoon, G.-S. Ahn, S.-S. Joo, and M. J. Lee, "PNP-MAC: preemptive slot allocation and non-preemptive transmission for providing QoS in body area networks," in Proceedings of the 7th IEEE Consumer Communications and Networking Conference (CCNC '10), IEEE, Las Vegas, Nev, USA, January 2010.

[52] H. Cao, S. González-Valenzuela, and V. C. M. Leung, "Employing IEEE 802.15.4 for quality of service provisioning in wireless body area sensor networks," in Proceedings of the 24th IEEE International Conference on Advanced Information Networking and Applications (AINA '10), pp. 902-909, IEEE, Perth, Australia, April 2010.

[53] M. M. Monowar, M. M. Hassan, F. Bajaber, M. Al-Hussein, and A. Alamri, "McMAC: towards a MAC protocol with multiconstrained QoS provisioning for diverse traffic in Wireless Body Area Networks," Sensors, vol. 12, no. 11, pp. 15599-15627, 2012.

[54] S. Kutty and J. A. Laxminarayan, "Towards energy efficient protocols for wireless body area networks," in Proceedings of the 5th International Conference on Industrial and Information Systems (ICIIS '10), pp. 31-34, IEEE, Mangalore, India, August 2010.

[55] K. A. Ali, J. H. Sarker, and H. T. Mouftah, "Urgency-based MAC protocol for wireless sensor body area networks," in Proceedings of the IEEE International Conference on Communications Workshops (ICC '10), IEEE, Cape Town, South Africa, May 2010.

[56] K. A. Ali, J. H. Sarker, and H. T. Mouftah, "A MAC protocol for cognitive wireless body area sensor networking," in Proceedings of the 6th International Wireless Communications and Mobile Computing Conference (IWCMC '10), pp. 168-172, ACM, Caen, France, July 2010.

[57] Y.-S. Seo, D.-Y. Kim, J. Cho, and B. Lee, “OCDP: a WBAN MAC protocol for contention-based medical and CE applications," in Proceedings of the 4th International Conference on Ubiquitous Information Management and Communication (ICUIMC '10), pp. 75-78, ACM, Suwon, Republic of Korea, January 2010.

[58] M. A. Ameen, J. Liu, S. Ullah, and K. S. Kwak, "A power efficient MAC protocol for implant device communication in wireless body area networks," in Proceedings of the 2011 IEEE 8th Annual Consumer Communications and Networking Conference (CCNC '11), pp. 1155-1160, IEEE, Las Vegas, Nev, USA, January 2011.

[59] M. A. Huq, E. Dutkiewicz, G. Fang, R. P. Liu, and R. Vesilo, "MEB MAC: improved channel access scheme for medical emergency traffic in WBAN," in Proceedings of the International Symposium on Communications and Information Technologies (ISCIT '12), pp. 371-376, IEEE, Queensland, Australia, October 2012.

[60] S. Ullah and K. S. Kwak, "An ultra low-power and trafficadaptive medium access control protocol for wireless body area network," Journal of Medical Systems, vol. 36, no. 3, pp. 10211030, 2012.

[61] S. Marinkovic and E. Popovici, "Ultra low power signal oriented approach for wireless health monitoring," Sensors, vol. 12, no. 6 , pp. 7917-7937, 2012.
[62] S. Ullah, "RFID-enabled MAC protocol for WBAN," in Proceedings of the IEEE International Conference on Communications (ICC '13), pp. 6030-6034, IEEE, Budapest, Hungary, June 2013.

[63] N. N. Bradai et al., "New priority MAC protocol for wireless body area networks," in Proceedings of the 3rd ACM MobiHoc Workshop on Pervasive Wireless Healthcare (MobileHealth '13), pp. 1-6, Bangalore, India, August 2013.

[64] G. Zhou, J. Lu, C.-Y. Wan, M. D. Yarvis, and J. A. Stankovic, "BodyQoS: adaptive and radio-agnostic QoS for body sensor networks," in Proceedings of the 27th IEEE Communications Society Conference on Computer Communications (INFOCOM '08), pp. 1238-1246, IEEE, Phoenix, Ariz, USA, April 2008.

[65] K. S. Kwak and S. Ullah, "A traffic-adaptive MAC protocol for WBAN," in Proceedings of the 2010 IEEE Globecom Workshops (GC '10), pp. 1286-1289, IEEE, Miami, Fla, USA, December 2010.

[66] K. M. Silva, M. R. Yuce, and J. Y. Khan, "A multiple access protocol for UWB wireless body area networks (WBANs) with narrowband feedback path," in Proceedings of the 4th International Symposium on Applied Sciences in Biomedical and Communication Technologies (ISABEL '11), ACM, Barcelona, Spain, October 2011.

[67] B. S. Kim and J. Cho, "A novel priority-based channel access algorithm for contention-based MAC protocol in WBANs," in Proceedings of the 6th International Conference on Ubiquitous Information Management and Communication (ICUIMC '12), ACM, Kuala Lumpur, Malaysia, February 2012.

[68] N. Mouzehkesh, T. Zia, and S. Shafigh, "Traffic aware fuzzytuned delay range for wireless body area networks medium access control protocol (MAC)," in Proceedings of the IEEE 8th International Conference on Intelligent Sensors, Sensor Networks and Information Processing: Sensing the Future (ISSNIP '13), pp. 60-65, IEEE, Melbourne, Australia, April 2013.

[69] M. H. Yaghmaee, N. F. Bahalgardi, and D. Adjeroh, "A prioritization based congestion control protocol for healthcare monitoring application in wireless sensor networks," Wireless Personal Communications, vol. 72, no. 4, pp. 2605-2631, 2013.

[70] R. Kong, C. Chen, W. Yu, B. Yang, and X. Guan, "Data priority based slot allocation for wireless body area networks," in Proceedings of the International Conference on Wireless Communications \& Signal Processing (WCSP '13), IEEE, Hangzhou, China, October 2013.

[71] J. Zhou, A. Guo, J. Xu, and S. Su, "An optimal fuzzy control medium access in wireless body area networks," Neurocomputing, vol. 142, pp. 107-114, 2014.

[72] S. Misra and S. Sarkar, "Priority-based time-slot allocation in wireless body area networks during medical emergency situations: an evolutionary game-theoretic perspective," IEEE Journal of Biomedical and Health Informatics, vol. 19, no. 2, pp. 541-548, 2015.

[73] E. Ibarra, A. Antonopoulos, E. Kartsakli, and C. Verikoukis, "HEH-BMAC: hybrid polling MAC protocol for WBANs operated by human energy harvesting," Telecommunication Systems, vol. 58, no. 2, pp. 111-124, 2014.

[74] L. Lin, C. Yang, K. J. U. Wong, H. Yan, J. Shen, and S. J. A. Phee, "An energy efficient MAC protocol for multi-hop swallowable body sensor networks," Sensors, vol. 14, no. 10, pp. 19457-19476, 2014.

[75] M. M. Alam, E. Ben Hamida, O. Berder, D. Menard, and O. Sentieys, "A heuristic self-adaptive medium access control for resource-constrained WBAN Systems," IEEE Access, vol. 4, pp. 1287-1300, 2016. 
[76] H. Chen, Z. Nie, K. Ivanov, L. Wang, and R. Liu, "A statistical MAC protocol for heterogeneous-traffic human body communication," in Proceedings of the IEEE International Symposium on Circuits and Systems (ISCAS '13), pp. 2275-2278, IEEE, Beijing, China, May 2013.

[77] J. Yu, L. Park, J. Park, S. Cho, and C. Keum, "CoR-MAC: contention over reservation MAC protocol for time-critical services in wireless body area sensor networks," Sensors, vol. 16, no. 5, pp. 656-675, 2016.

[78] S. Rashwand, J. Mišić, and H. Khazaei, "IEEE 802.15.6 under saturation: some problems to be expected," Journal of Communications and Networks, vol. 13, no. 2, pp. 142-148, 2011. 


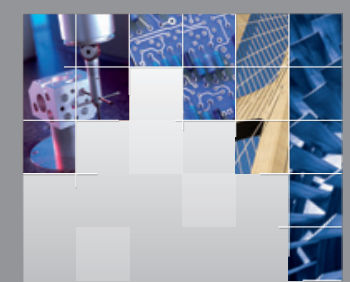

\section{Enfincering}
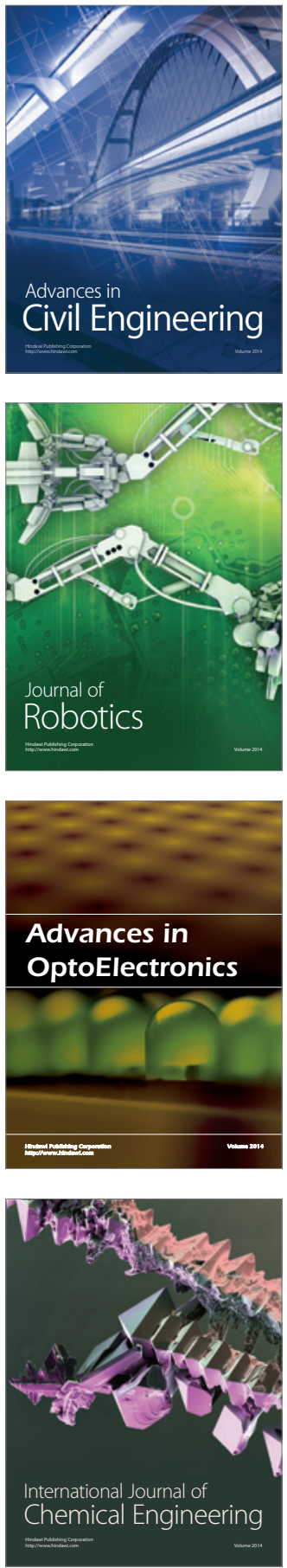

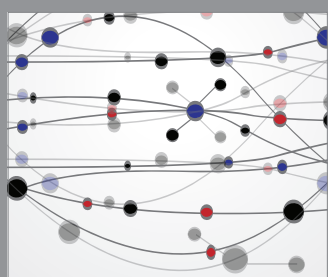

The Scientific World Journal

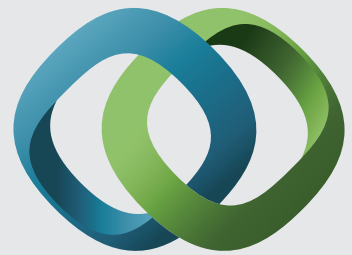

\section{Hindawi}

Submit your manuscripts at

https://www.hindawi.com
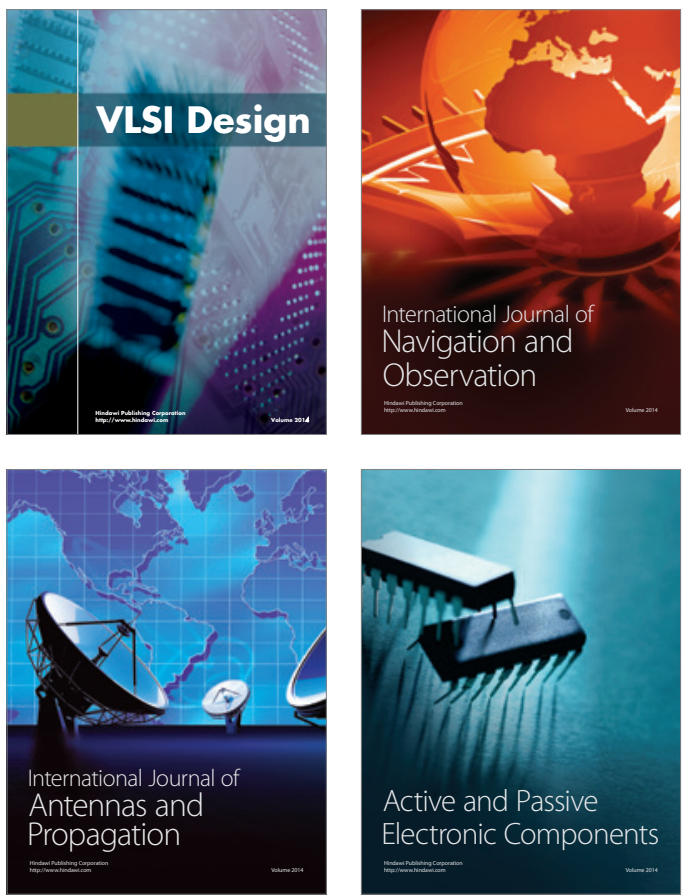
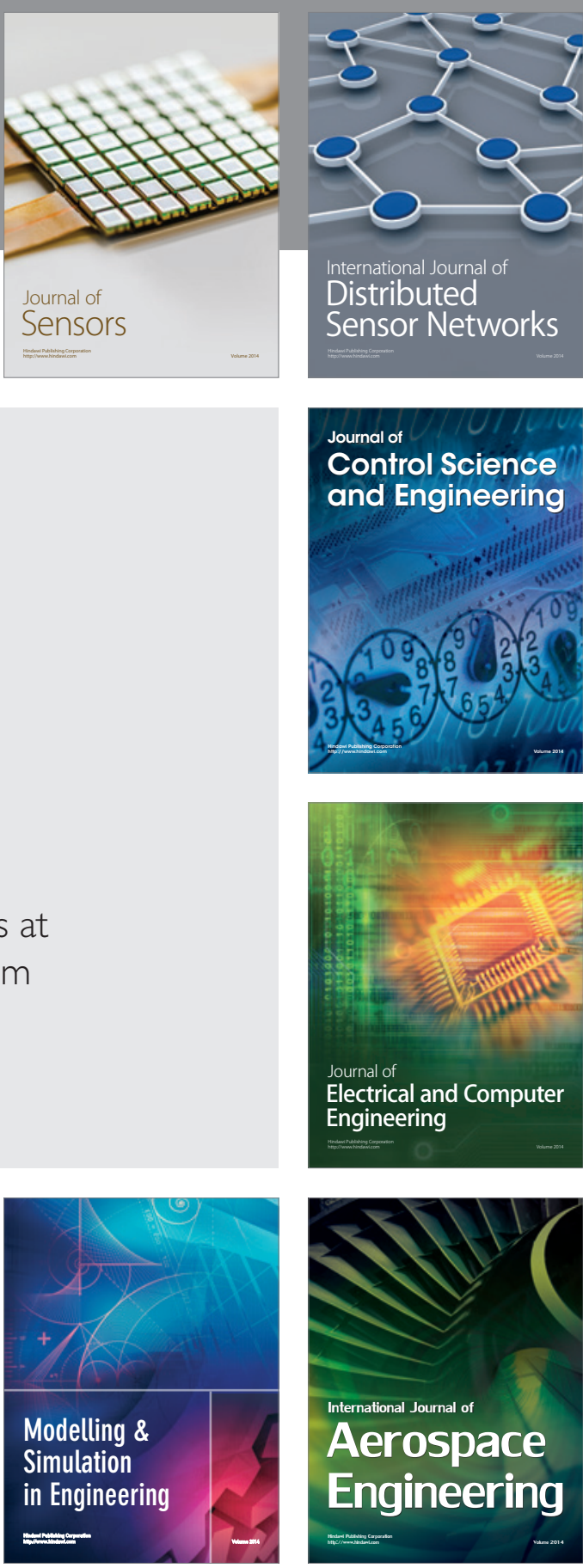

International Journal of

Distributed

Sensor Networks

$-$

Joumal of

Control Science

and Engineering
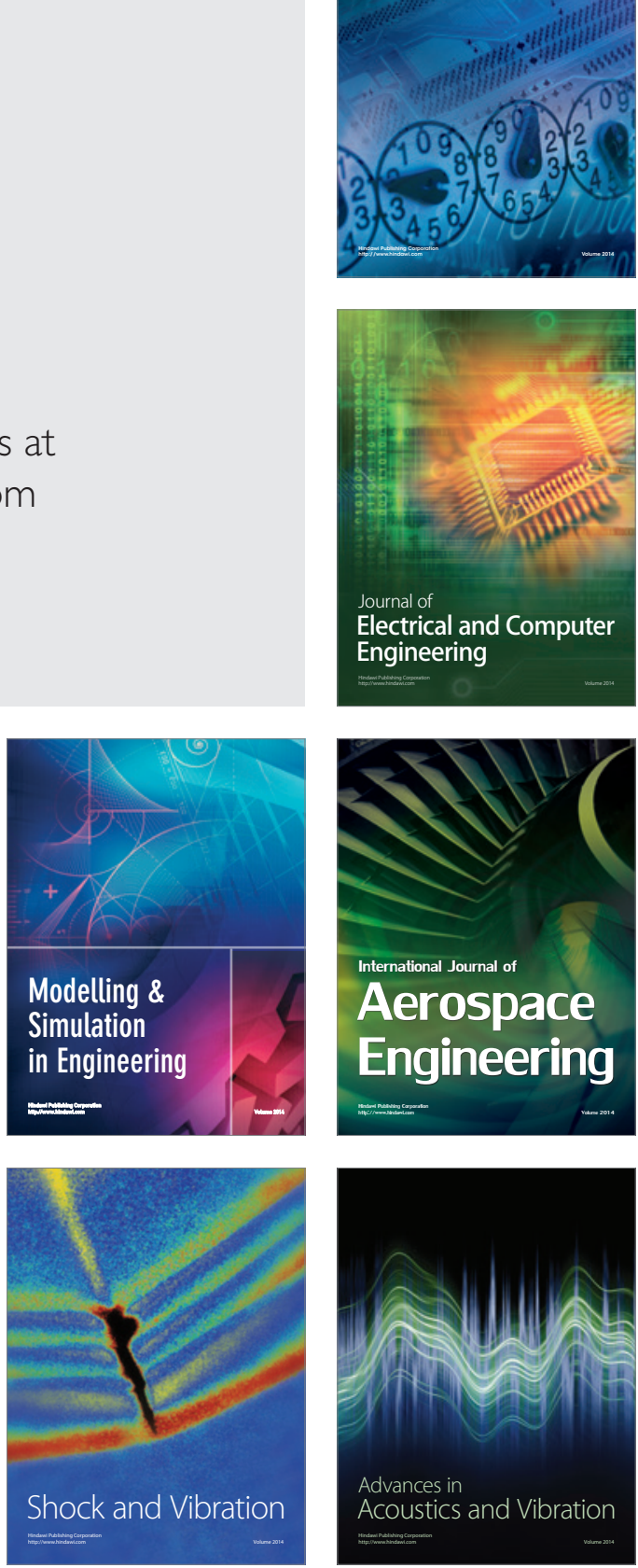